\title{
EXPRESSION OF CYTOKERATIN 18 IN THE PERIPHERAL NERVES
}

\author{
Marettová, E. \\ University of Veterinary Medicine and Pharmacy, Komenského 73, 04181 Košice \\ The Slovak Republic \\ elena.marettova@uvlf.sk
}

\section{ABSTRACT}

The perineurium constitutes the basis for the regulation of endoneurial fluid homeostasis. In the work presented here, cytokeratin 18, as an immunohistochemical marker for epithelial cells, was used to identify the perineurium in the peripheral nerves of two species. Two organs, rich in peripheral nerves, were used; the tongue of the bull and the ductus deferens of the male goat. Special attention was paid to one of the the nerve sheath cells - the perineurial cells of myelinated nerves in the skeletal muscle of the tongue and in the smooth muscle in the wall of the ductus deferens. A positive reaction to cytokeratin 18 was found in the perineurial cells of the perineurial sheath in the nerves of various sizes. No difference in the reactivity was observed between the peripheral nerves of the tongue and that of the ductus deferens.

Key words: bull; cytokeratin 18; ductus deferens; goat; peripheral nerves; tongue

\section{INTRODUCTION}

Histologically, the peripheral nerves consist of axons and coats - the endoneurium, perineurium, and epineurium. The endoneurium surrounds each nerve fibre, while the perineurium isolates individual nerve fascicles. The epineurium forms the outer surface of a peripheral nerve and consists of connective tissue. The perineurium forms a protective barrier around nerve fascicles. It is made of layers of perineurial cells surrounded by a basement membrane and collagen fibers, forming a concentrically laminated structure around a single nerve fascicle. Morphologically, perineurial cells resemble fibroblasts. The perineurial cells are characterized by distinct ultrastructural features which include: non-branching thin cytoplasmic processes coated by an external lamina and joined at their ends by tight junctions, few organelles, actin and vimentin filaments, and numerous pinocytotic vesicles. They are 3-dimensionally flattened, polygonal, or squamous cells, and form many concentric layers around the axons [15], [16]. Functionally, the perineurium modulates external stretching forces that could be potentially harmful for nerve fibers, and addition- 
ally, along with endoneurial vessels, forms the blood-nerve barrier [17]. The perineurium constitutes the basis for the regulation of endoneurial fluid homeostasis and therefore is comparable to the blood-brain barrier of the CNS. It protects the Schwann cell axon units and the endoneurial connective tissue from ionic alterations, antigens, toxins and infectious agents.

Cytokeratins (CK) are considered markers of epithelial differentiation and the cytokeratins typical of simple epithelia, with the primary keratin pair $8 / 18$ as a significant component, have been detected in neuroectodermal tissues [2],[ 6], [13]. In lower vertebrates, immunoreactivity for keratin 8 and 18 has been reported in nonepithelial cells; particularly in mesenchymal progenitor cells of regenerating complex body structures [3]. In contrast, cytokeratin intermediate filaments (IF) and desmosomes have not been detected in the glial cells of the brain and spinal cord, or in certain peripheral nerves [15].

Multiple pathologic conditions associated with the perineurium have been described, including certain non-epithelium-derived tumors. Perineurial-like cells were noted in three tumors and cells intermediate between perineurial and Schwann cells [10]. Cytokeratins have been reported to occur, occasionally and focally in certain human ependymomas, astrocytomas, and primitive neuroectodermal tumors [4], [8], [18]. To clarify the cellular composition of various peripheral nerve tumorous lesions, the expression of several markers specific to nerve sheath cells, were immunohistochemically investigated [11]. The aim of this study was to identify localized perineurial cells by the immunohistochemical marker cytokeratin 18 in the tongue and $d u c$ tus deferens of the adult bull and goat (respectively).

\section{MATERIALS AND METHODS}

Tissue samples of the tongue of the bull and the ductus deferens of the goat were used in this study. Samples of the tissues were fixed in $10 \%$ neutral formalin in $0.2 \mathrm{~mol}$ phosphate buffer for $24 \mathrm{~h}$ and thereafter routinely embedded in paraffin. For the immunohistochemical study, the deparaffinized and rehydrated sections were rinsed in phosphatebuffered saline (PBS) and endogenous peroxidase was blocked by incubation with $3 \% \mathrm{v} / \mathrm{v}_{2} \mathrm{O}_{2}$ for 20 minutes. After rinsing with $\mathrm{PBS}$, the sections were incubated with $1 \%$ w/v Bovine Serum Albumin (BSA) in PBS at room tempera- ture to prevent unspecific binding. The sections were then incubated in a humidified chamber overnight with primary antibodies. The washed sections were incubated overnight with monoclonal antibody against cytokeratin 18 (mouse IgG2b, clone 611 B-1, Sigma). After incubation, the sections were stained using the avidin-biotinylated-peroxidase complex detection system (ABC kit; Vector Laboratories, Burlingame, $\mathrm{CA}$ ). The slides were then washed three times for 5 min with PBS. The specific binding was visualized with the peroxidase substrate $3,3^{\prime}$-diaminobenzidine (DAB). For negative controls, the first antibody was substituted by PBS or by normal rabbit serum. Sections were counterstained with Mayer's hematoxylin and methylene blue.

\section{RESULTS}

Perineurial cells of the perineurium found in both organs are elongated spindle shaped cells with eosinophilic cytoplasm with curved or wavy thin nuclei and thin, elongated cytoplasmic processes, arranged in lamellae. Microscopically, two components were found in the perineurium: fibrous perineurium, an outer layer of collagenous connective tissue and perineural epithelium, and an inner layer of squamous epithelial cells. Collagen fibrils are dispersed between the layers. Perineual epithelium forms a continuous sheet. The number of layers decrease in number as fascicles become smaller (Figures 1-2).

Positive reactions to CK 18 in both organs studied were found in the perineurial sheaths of the nerves of various sizes. The intensity of reactivity was equal in all perineurial cells and was equal in the cells body and in cytoplasmic processes which formed the long flatened lamellae. The endoneurium was not stained with CK 18 (Figures 1-3).

\section{DISCUSSION}

It is widely accepted that cytokeratins are usually restricted to epithelium-derived tissues. This has been elaborated in several mammals, notably: man, cow, rat and mouse (and also in birds). In the fetal neuroectodermal tissues studied, the cytokeratin pairs $8 / 18$ are the first ones to be expressed during embryonic development [13]. Cytokeratins 8 and 18, occasionally accompanied by CK19, can be seen, often transiently, in certain non-epithelial tissues, 


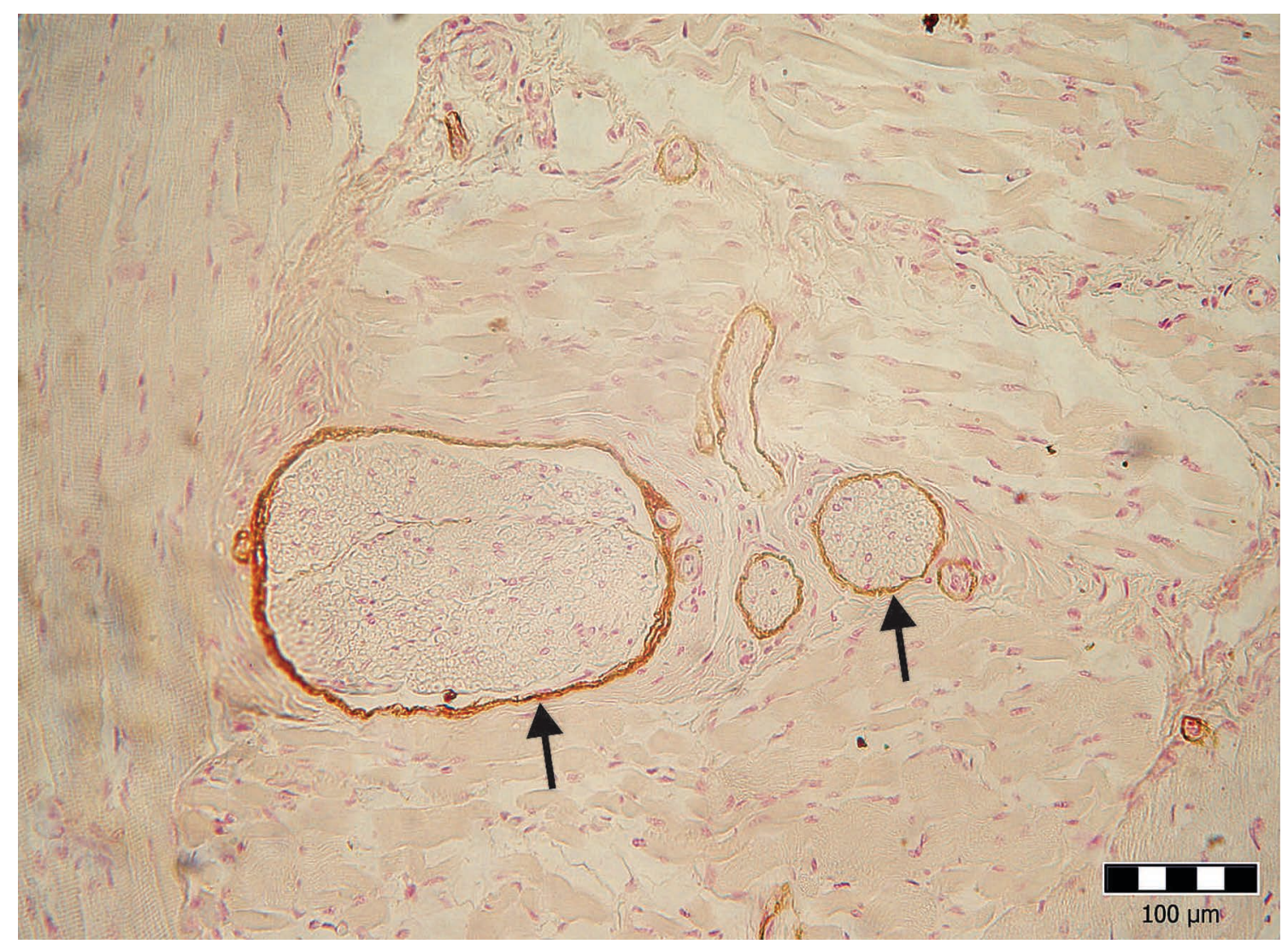

Fig. 1. Immunoreactivity for CK 18. The nerves in cross sections in the tongue muscle. Perineurium is positively stained for CK 18 (arrows)

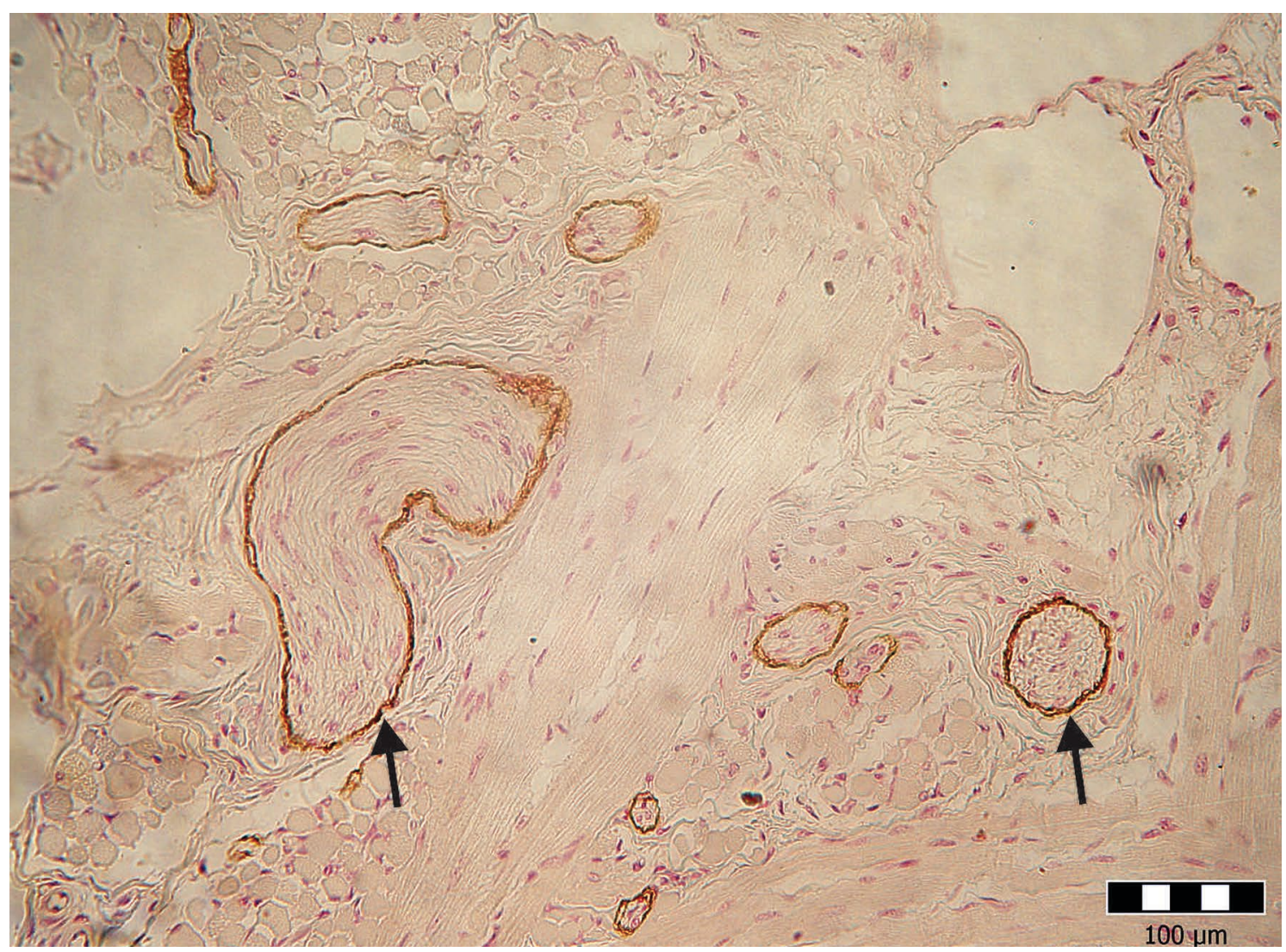

Fig. 2. Immunoreactivity for CK 18. The nerves of various sizes in cross and oblique sections in tongue muscle. Perineurium is positively stained for CK 18 (arrows) 


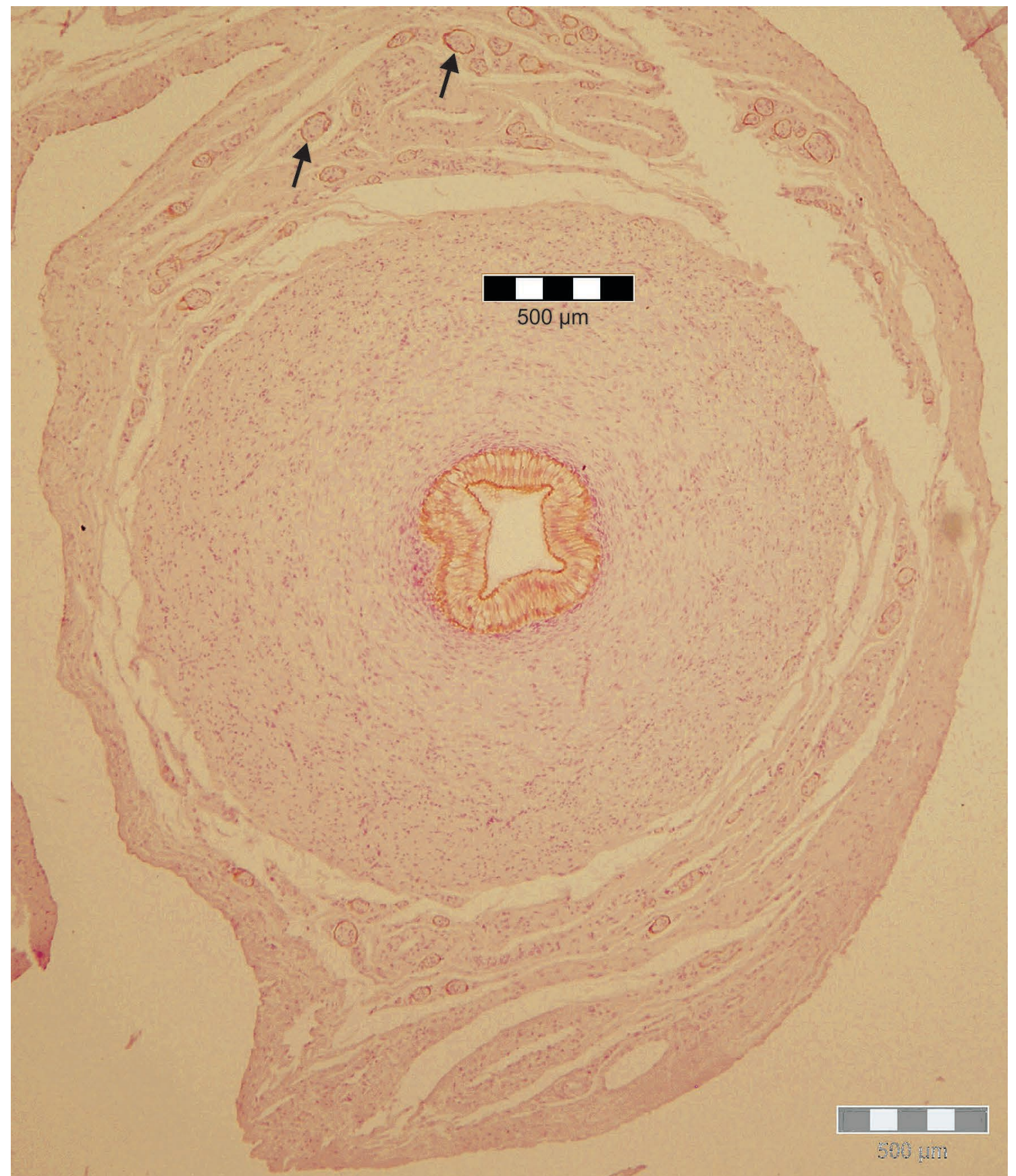

Fig.3. Immunoreactivity for CK 18. The small nerves in cross sections in the connective tissue of the ductus deferens. Perineurium is positively stained for CK 18 (arrows)

especially embryonal ones, and in a rare subtype of human endothelial cells [6], [12]. A small amounts of cytokeratins 8,18 , and 19 (or their homologues) have been identified in certain amphibian and human smooth muscle tissues [12].

Numerous studies of the embryogenesis of the avian and mammalian nervous systems and of in vitro differentiation of neural cells have shown that differentiating glial and neuronal cells are characterized by the absence of cyto- keratin [7]. In higher vertebrates, the cytoskeleton of glial cells are characterized by masses of intermediate filaments (IF) that contain the hallmark protein of glial differentiation (the glial filament protein) and also by the absence of cytokeratin IFs.

The single or multi-layered sheaths of epithelioid cells surrounding peripheral nerves (perineurial cells) or structures of the central nervous system, including the optic 
nerve (arachnoid cells), show remarkable interspecies differences in their cytoskeletal complements [2]. In some amphibia, the perineurial cells of the sheaths of peripheral nerves, as well as the arachnoidal cells of the meninges, are interconnected by desmosomes and contain cytokeratin intermediate filaments; an occurrence that has also been reported for some mammals [1]. Among higher vertebrates, a similar situation is found in the bovine and chicken nervous systems; the perineurial cells of many nerves contain cytokeratin intermediate filaments. Intense staining for cytokeratins was observed, not only in the meningeal cells, but also in the glial elements of the nerve interior. In contrast, in rat perineurial cells, significant reactions have not been observed for cytokeratins or for desmosomal proteins [2]. In our study, CK 18 was observed in the peripheral nerves of both organs studied and thus, both animal species.

The cytogenesis of the perineurium remains disputable, with morphologic, immunohistochemical, and experimental evidence supporting an origin from the fibroblast, Schwann cell, and arachnoid cap cells [5]. It was found that all meningeal layers of the spinal cord, the perineurium and the endoneurium of peripheral nerves, as well as the capsular and inner space cells of Herbst sensory corpuscles, develop from the local mesenchymal cells, whereas Schwann cells and cells of the inner core of sensory corpuscles are of neural crest origin [9]. The selective mesenchymal expression of keratins includes the presence of keratins 7,8 and 18 in some smooth muscle cells (myometrium, vascular and some parenchymal smooth muscle) and expression of keratins 7 and 18 in some vascular endothelial cells [14]. Moreover, small amounts of cytokeratins 8, 18, and 19 (or their homologues) have been recently identified in certain amphibian and human smooth muscle tissues [12]. Thus, the expression of cytokeratins may be characteristic of a certain type of astrocytes that remains in an embryonal proliferative state.

\section{CONCLUSIONS}

A positive reaction to cytokeratin 18 was found in the perineurial sheath of the nerves in the skeletal muscle of the tongue of the bull and in the smooth muscle of the wall of the ductus deferens in the goat. No difference in the reactivity was observed between the peripheral nerves of the organs studied. The morphological features common for perineurial cells and described in the peripheral nerves were confirmed by immunostaining in the tongue and $d u c$ tus deferens of the bull and goat.

\section{ACKNOWLEDGEMENT}

This research was supported by Referential Laboratory for Pesticides, University of Veterinary Medicine and Pharmacy, Košice.

\section{REFERENCES}

1. Achtstitter, T.R., Moll, A., Anderson, C., Kuhn, S., Pitz, K., Schwechheimer, W., Franke, W., 1986: Expression of glial filament protein (GFP) in nerve sheaths and non-neural cells re-examined using monoclonal antibodies, with special emphasis on the co-expression of GFP and cytokeratins in epithelial cells of human salivary gland and pleomorphic adenomas. Differentiation, 31, 206-227.

2. Achtstätter, T., Fouquet, B., Rungger-Brändle, E., Franke, W. W., 1989: Cytokeratin filaments and desmosomes in the epithelioid cells of the perineurial and arachnoidal sheaths of some vertebrate species. Differentiation, 40, 129-149.

3. Corcoran, J. P., Ferretti, P., 1997: Keratin 8 and 18 expression in mesenchymal progenitor cells of regenerating limbs is associated with cell proliferation and differentiation. Dev. Dyn., 210, 355-370.

4. Dehner, L.P., Abenoza, P., Sibley, R. K., 1988: Primary cerebral neuroectodermal tumors: neuroblastoma, differentiated neuroblastoma, and composite neuroectodermal tumor. Ultrastruct. Pathol., 12, 479-494.

5. Erlandson, R. A., 1991: The enigmatic perineurial cell and its participation in tumors and in tumorlike entities. Ultrastruct. Pathol., 15, 335-351.

6. Franke, W. W., Jahn, L., Knapp, A.C., 1989: Cytokeratins and desmosomal proteins in certain epithelioid and nonepithelial cells. In Osbom, M., Weber, K. (Eds.): Cytoskeletal Proteins in Tumor Diagnosis, Cold Spring Harbor Laboratory Press, NY, $151-172$.

7. Gould, V.E., Kouk oulis, G.K., Jansson, D.S., Nagle, R.B., Franke, W.W., Moll, R., 1990: Coexpression patterns of vimentin and glial filament protein with cytokeratins in the normal, hyperplastic, and neoplastic breast. Am. J. Pathol., 137, 1143-1155. 
8. Gu, H-Y., Wei, Z-M., Lin, D-L., Zhao, H., Hao F-Y., 2014: Soft tissue perineurioma with peripheral lymphoid cuff of the tongue: a case report and literature review. Int. J. Clin. Exp. Med., $7,323-326$

9. Halata, Z., Grim, M., Christ, B., 1990: Origin of spinal cord meninges, sheaths of peripheral nerves, and cutaneous receptors including Merkel cells. Anat. Embryol., 182, 529-537.

10. Hirose, T., Scheithauer, B. W., Sano, T., 1998: Perineurial malignant peripheral nerve sheath tumor (MPNST): a clinicopathologic, immunohistochemical, and ultrastructural study of seven cases. Am. J. Surg. Pathol., 22, 1368-1378.

11. Hirose, T., Tani, T., Shimada, T., Ishizawa, K., Shimada, S., Sano, T., 2003: Immunohistochemical demonstration of EMA/ Glut1-positive perineurial cells and CD34-positive fibroblastic cells in peripheral nerve sheath tumors. Mod. Pathol.,16, 293-298.

12. 12. Jahn, L., Fouquet, B., Rohe, K., Franke, W. W., 1987: Cytokeratins in certain endothelial and smooth muscle cells of two taxonomically distant vertebrate species, Xenopus laevis and man. Differentiation, 36, 234-254.
13. Kasper, M., 1992: Cytokeratins in intracranial and intraspinal tissues. Adv. Anat. Embryol. Cell Biol., 126, 1-82.

14. Kuruc, N., Franke, W. W., 1988: Transient coexpression of desmin and cytokeratin filament in developing myocardial cells of some vertebrate species. Differentiation, 38, 177-193.

15. Ochi, A., Ochiai, K., Hatai, H., Umemura, T., 2008: Naturally occurring multiple prineuriomas in a chicken (Gallus domesticus). Vet. Pathol., 45, 685-689.

16. Ortiz-Hidalgo, C., Weller, R.O., 1997: Peripheral nervous system. In Sternberg, S.S., (Ed.): Histology for Pathologists. 2nd edn., Lippincott-Raven, Philadelphia, PA, 285-311.

17. Piña-Oviedo, S., Ortiz-Hidalgo, C., 2008: The normal and neoplastic perineurium: a review. Adv. Anat. Pathol., 15, 147-164.

18. Wang, L.M., Zhong, Y.F., Zheng, D.F., Sun, A.P., Zhang, Y.S., Dong, R.F., Pan, Y., 2014: Intraneural perineurioma affecting multiple nerves: a case report and literature review. Int. J. Clin. Exp. Pathol., 7, 3347-3354.

Received March 9, 2016 